\title{
AS CONEXÕES ENTRE O MARKETING E A LOGÍSTICA NA BUSCA DO VALOR AO CLIENTE
}

\author{
Carlos José Guimarães Cova D.Sc. (UFF)
}

\begin{abstract}
RESUMO
Neste artigo procuramos demonstrar que é cada vez maior a interdependência entre o Marketing e a Logística, pois cada vez mais se reconhece o poder do serviço ao cliente como um meio potencial de diferenciação entre as empresas. Em regra, a maior parte dos livros-texto apresenta o Marketing como sendo o gerenciamento dos 4 "Ps", designados por produto, preço, promoção e praça (também chamada de ponto de venda). Até hoje a ênfase do Marketing recaia sobre os três primeiros "Ps". A praça, que pode ser descrita por intermédio do antigo clichê, "o produto certo, no lugar certo, na hora certa", de um modo geral não era muito enfatizado nos esforços da função marketing. Veremos que a disponibilidade dos produtos passou a ser determinante para a decisão de venda. Se o produto está disponível agora, então o cliente compra, pois a disponibilidade para venda passa a ser um diferencial atrativo para o cliente, visto que o produto já se "commoditizou" (todas as marcas são similares). Não obstante, a disponibilidade é um elemento do serviço de suporte ao cliente, bem como um dos aspectos tratados pelo gerenciamento logístico. Será dado destaque também para a importância do valor ao cliente. $O$ valor ao cliente, por sua vez, pode ser compreendido como sendo a forma pela qual o cliente percebe as ofertas da empresa, aí incluídos os produtos, os serviços e outros bens intangíveis. Estas percepções dos clientes podem ser classificadas em múltiplas dimensões: conformidade com as exigências; seleção de produtos; preço e marca; serviços com valor agregado; relacionamentos e experiências.
\end{abstract}

Palavras-Chave: Logística. Marketing. Valor ao cliente.

\begin{abstract}
This article is trying show that increasing the interdependence of the Marketing and Logistics, as increasingly is recognized the power of customer service as a potential means of differentiation between the companies. As a rule, most of the text-books introduced the Marketing as the management of 4 "Ps", designated by product, price, promotion and place (also called point of sale). The square, which can be described through the former clichê, "the right product, in the right place, at the right time," in general was not much emphasized in the efforts of the marketing function. We will see that the availability of products has become crucial to the decision to sell. If the product is available now, then the customer buys, as the availability for sale becomes a differential attractive for the customer). However, availability is an element of the service, customer support, as well as one of the aspects dealt with by logistics management.
\end{abstract}

Key-Words: Logistics. Marketing. Customer Value. 


\section{A CONEXÃO FUNDAMENTAL ENTRE O MARKETING E A LOGÍSTICA}

É cada vez maior a interdependência entre o Marketing e a Logística, conforme podemos verificar em Christopher (2007, p.43): "cada vez mais se reconhece o poder do serviço ao cliente como um meio potencial de diferenciação". De acordo com este autor, a maior parte dos livros-texto apresenta o Marketing como sendo o gerenciamento dos 4 "Ps", designados por produto, preço, promoção e praça (também chamada de ponto de venda). Até hoje a ênfase do Marketing recaia sobre os três primeiros "Ps". A praça, que pode ser descrita por intermédio do antigo clichê, "o produto certo, no lugar certo, na hora certa", de um modo geral não era muito enfatizado nos esforços da função marketing.

Não obstante, atualmente cresce o número de mercados nos quais o poder da marca está declinando, de tal maneira que os consumidores estão mais propensos a aceitar produtos substitutos. Em razão da convergência tecnológica, também se reduz a diferença entre as tecnologias, de sorte que se torna mais difícil manter uma vantagem competitiva em razão de características do produto em si mesmo. Num contexto assim, o nível de serviço ao cliente é um poderoso diferencial competitivo capaz de proporcionar a diferença entre a oferta de uma empresa e a de seus concorrentes.

Verificamos hoje em dia que a estratégia competitiva das empresas está focada na agregação de valor ao cliente. Tal circunstância decorre da ação de dois fatores que se combinam e se reforçam: o incremento da sofisticação do cliente; a tendência a uma certa "commoditização" dos produtos, fato que enfraquece a força da marca e ocorre em razão da convergência tecnológica.

É fácil compreender que os indivíduos aumentam seu grau de exigência à medida que vão amadurecendo. Por exemplo, quando ainda somos jovens universitários não nos incomodamos em viajar grandes percursos de ônibus e, ao chegarmos, ninguém se aborrece por ficar alojado com dezenas de colegas em um galpão, dormindo no chão.

Tudo isso soa como divertimento e novidades. Mas, depois que a pessoa amadurece, constitui família e dispõe de uma boa renda mensal provavelmente vai querer mais conforto, comodidade e privacidade. Portanto, para um cliente desses não adianta oferecer uma viagem como essa dos universitários, pois ele não está disposto a abrir mão de seu conforto. Ou seja, ele sofisticou seu grau de exigência do produto.

A questão da "commoditização" dos produtos é um pouco mais sutil. 0 termo commoditie é usado para designar geralmente um produto primário com grande número de fornecedores no comércio internacional, tal como café, algodão e minério de ferro.

Sua principal característica é a ausência de alguma diferenciação que permitisse tornálo distinto, em face dos demais produtos existentes no mercado. Neste caso, a marca não faz a menor diferença e o que importa para o consumidor final é o preço. Tal situação está começando a ocorrer também com os produtos que têm tecnologia incorporada. Por exemplo, quem pretende comprar um aparelho de celular vai encontrar neste produto os seguintes itens tecnológicos: internet; câmera fotográfica; jogos; CPU; MP3; agenda etc. Todas essas tecnologias convergem para o mesmo produto. Isto é o que chamamos de convergência tecnológica, e estará disponível a despeito da marca do produto adquirido. É por isso é que a tal "commoditização" enfraquece a força da marca, pois todas as marcas (Motorola, Nokia, Samsung etc.) fazem igualmente uso da convergência tecnológica em seus produtos.

Em face destas evidências, a própria disponibilidade dos produtos passa a ser determinante 
para a decisão de venda. Se o produto está disponível agora, então o cliente compra, pois a disponibilidade para venda passa a ser um diferencial atrativo para o cliente, visto que o produto já se "commoditizou" (todas as marcas são similares). Não obstante, a disponibilidade é um elemento do serviço de suporte ao cliente, bem como um dos aspectos tratados pelo gerenciamento logístico.

As empresas bem-sucedidas atualmente são aquelas capazes de explorar estas circunstâncias presentes no ambiente de mercado de tal forma a oferecerem maior valor ao cliente. Não é apenas nos mercados de consumidores finais que tal fenômeno tem se manifestado. Também nos mercados empresariais é perceptível a força do serviço ao cliente como sendo um determinante de compra.

Dessa forma, o êxito dos negócios tende a ser determinado pelo nível de valor entregue aos clientes nos mercados em que atuam. Uma definição de valor entregue ao cliente pode ser a diferença entre os benefícios percebidos a partir de uma transação e os custos totais incorridos nela, tal como a expressão a seguir:

\section{VALOR PARA O CLIENTE = percepção de benefícios - custo total de propriedade}

É mais apropriado o termo custo total de propriedade, no lugar apenas de preço, porque uma transação costuma implicar em outros custos adicionais ao preço, tais como manutenção, processamento dos pedidos e baixas no estoque. Da mesma forma, os benefícios percebidos numa transação costumam ser maiores do que as características tangíveis dos produtos. Como exemplo, dois produtos de marcas diferentes podem evidenciar o mesmo desempenho técnico, mas um deles pode oferecer um melhor nível de suporte ao cliente, fato que dá um caráter utilitário maior ao referido produto.

Esta forma de caracterizar a relação entre os benéficos e custos permite uma definição mais simples de vantagem competitiva, que pode ser entendida como sendo a capacidade que uma empresa possui de entregar um maior valor ao cliente do que as empresas concorrentes. $\mathrm{Ou}$ seja, a sua relação benefício-custo é maior do que das demais empresas que atuam no mesmo segmento de mercado.

É possível conceber uma visão expandida da relação custo-benefício que oferece uma maior evidência do papel que o gerenciamento logístico desempenha na promoção do valor para o cliente. Dessa forma, o valor para o cliente pode ser assim visualizado:

VALOR PARA $=\frac{\text { Qualidade X Serviço }}{\text { Custo X Tempo }}$
O CLIENTE

O gerenciamento logístico impacta tanto o numerador quanto o denominador da equação acima. Passemos a analisar cada um dos elementos que constituem esta expressão:

1 - Qualidade: este elemento representa a funcionalidade o desempenho e a especificação técnica da oferta.

2 - Serviço: é o elemento que manifesta-se por intermédio da disponibilidade do produto, do suporte e do compromisso com o cliente.

3 - Custo: o elemento custo refere-se a todos os custos da transação do cliente. 
4 - Tempo: este elemento refere-se aos lead times envolvidos na operação.

A manutenção da vantagem competitiva requer que a empresa mantenha um programa contínuo de investimentos em aperfeiçoamento e inovação.

As empresas de sucesso no atual ambiente competitivo foram aquelas que souberam deslocar o foco dos aspectos tradicionais do marketing e do gerenciamento logístico para a promoção do valor ao cliente. Tradicionalmente, o marketing esteve focado nos seus aspectos tradicionais, quais sejam: o desenvolvimento de produtos, a realização de atividades promocionais e a busca de preços competitivos. A despeito do fato de que estes aspectos sejam condições necessárias para o êxito da estratégia empresarial, hoje eles não são mais suficientes.

Da mesma forma, a orientação tradicional do gerenciamento logístico tem estado focada na redução de custos como sendo um fim em si mesma. Ocorre que a redução de custos apenas é válida se não comprometer a criação de valor para o cliente. Dessa forma, uma estratégia logística de baixo custo pode resultar numa logística eficiente, mas não numa logística eficaz.

É preciso também compreender que o marketing tradicionalmente atuou de forma a promover a marca e "empurrar" para o mercado os produtos da empresa. Antes de interagir com a empresa, o cliente pode ser considerado como sendo apenas uma entidade abstrata, que a microeconomia designa por consumidor. Mas, após interagir com a empresa e estabelecer uma série de vínculos este consumidor torna-se o cliente a sua acepção mais relevante, ou seja, aquele que vai receber um conjunto de benefícios advindos da sua transação com a empresa.

Com base neste raciocínio, é possível visualizar uma nova perspectiva de relacionamento entre o gerenciamento logístico da cadeia de suprimentos como um todo e a efetividade da função marketing, conforme a figura a seguir:

\begin{tabular}{|c|c|c|c|c|c|c|}
\hline $\begin{array}{l}\text { Atração do } \\
\text { consumidor }\end{array}$ & $\mathbf{X}$ & $\begin{array}{l}\text { Relações com } \\
\text { clientes }\end{array}$ & $\mathbf{X}$ & $\begin{array}{l}\text { Eficiência } \\
\text { logística }\end{array}$ & $=$ & $\begin{array}{l}\text { Marketing } \\
\text { efetivo }\end{array}$ \\
\hline $\begin{array}{l}\text {-Valor da } \\
\text { marca } \\
\text {-Imagem da } \\
\text { empresa } \\
\text {-Disponibi- } \\
\text { lidade }\end{array}$ & & $\begin{array}{l}\text {-Serviços ao } \\
\text { cliente } \\
\text {-Parcerias e } \\
\text { facilidades } \\
\text {-Pronta } \\
\text { resposta }\end{array}$ & & $\begin{array}{l}\text {-Flexibilidade } \\
\text {-Fornecedores } \\
\text { de baixo custo } \\
\text {-Uso intensivo } \\
\text { dos ativos }\end{array}$ & & \begin{tabular}{|l}
-Participação \\
no mercado \\
-Retenção dos \\
clientes \\
-Maiores \\
retornos sobre \\
o investimento
\end{tabular} \\
\hline
\end{tabular}

Com base nesta abordagem, pretendemos destacar o efeito multiplicador que cada componente acarreta no conjunto completo, com destaque para o componente específico do gerenciamento logístico.

\section{AS DIMENSÕES DO VALOR AO CLIENTE:}

Conforme assinalam SimChi-Levi et Alii (2003, p. 212) o importante não é o produto ou serviço isoladamente, mas sim o valor percebido pelo cliente no conjunto de relações com a empresa. Dessa forma, a maneira pela qual a empresa mede a qualidade de seus produtos e serviços deixou de ser a garantia interna desta qualidade, para se concentrar no valor ao 
cliente, passando pela satisfação externa do cliente.

Os tradicionais indicadores internos de qualidade, tais como o número de defeitos de cada produto, foram preponderantes na fase da chamada produção orientada para o abastecimento. A idéia de satisfação do cliente estava focada nos atuais clientes da empresa e no uso que fazem dos seus produtos, bem como a impressão que têm dos seus serviços. Tal perspectiva permitiu a geração de preciosas informações sobre os clientes, gerando idéias de melhorias de desempenho. A ênfase atual no valor ao cliente transcende estas duas perspectivas anteriores, indo além e tentando estabelecer a razão pela qual um cliente escolhe um determinado produto em vez de outro, analisando toda a linha de produtos, serviços e aspectos intangíveis que constituem o escopo de atuação da empresa.

0 ato de pensar em termos de valor ao cliente oferece uma visão mais ampla sobre as ofertas e os clientes da empresa. Permite saber por que os clientes resolvem comprar, continuam comprando ou deixam de comprar. Indaga acerca de quais são as necessidades dos clientes e como elas podem ser satisfeitas. Adicionalmente, também evidencia quais são os clientes lucrativos e quais aqueles que acabam gerando perdas para a empresa. É preciso que o gestor analise as suposições ou hipóteses sobre as fontes de valor para o cliente para conseguir enfrentar os trade-offs corretamente.

Podemos citar alguns exemplos desses trade-offs que ensejarão uma análise mais cuidadosa, e que se constituem em questões fundamentais para qualquer negócio, bem como a base de orientação da estratégia corporativa.

- o cliente valoriza mais os preços baixos ou os serviços eficientes de suporte?

- o cliente prefere preços menores ou a possibilidade de entrega imediata?

- o cliente prefere comprar o item numa loja especializada ou numa grande loja de departamentos?

É importante destacar que a logística, que era antes considerada como sendo uma função de retaguarda, passou a ser uma função de maior visibilidade no contexto da gestão da cadeia de suprimentos, em razão desta mudança de perspectiva. Assim, a gestão da cadeia de suprimentos passa a ser um importante componente no atendimento das necessidades dos clientes e na agregação de valor, pois é a gestão da cadeia de suprimentos que vai determinar a disponibilidade dos produtos, a rapidez com que chegarão aos mercados e o custo da operação.

Não obstante, a noção de valor para o cliente também é um elemento determinante do tipo de cadeia de suprimentos que é satisfatória para atender o cliente, bem como do tipo de serviço que é capaz de reter este mesmo cliente. Para cada tipo de produto ou serviço, bem como para as distintas manifestações de valor contidos na oferta ao cliente, deverá ser elaborada uma estratégia adequada.

Um interessante exemplo desta afirmação é dado por SimChi-Levi et Alii (2003, p. 214), quando nos sugere as seguintes hipóteses:

- se o cliente prefere comprar em grandes lojas de departamentos, é preciso ficar em condições de ofertar múltiplos produtos e opções, ainda que isto implique em maiores custos de gerenciamento de estoques. 
- $\quad$ se o cliente atribui valor para produtos inovadores, então a cadeia de suprimentos das empresas que os produzem necessitam ficar em condições de atende-los enquanto persistir a demanda pela inovação.

- ou ainda, se a empresa promete produtos personalizados, então a cadeia de suprimentos precisa ser suficientemente flexível para viabilizar uma infra-estrutura que permita prover esta oferta.

Ou seja, é preciso considerar a cadeia de suprimentos como elemento fundamental de qualquer estratégia de produto e de vendas, na medida em que ela, por si mesma, é capaz de proporcionar vantagens competitivas, aumentando o nível de valor ao cliente.

0 valor ao cliente, por sua vez, pode ser compreendido como sendo a forma pela qual o cliente percebe as ofertas da empresa, aí incluídos os produtos, os serviços e outros bens intangíveis. Estas percepções dos clientes podem ser classificadas em múltiplas dimensões: conformidade com as exigências; seleção de produtos; preço e marca; serviços com valor agregado; relacionamentos e experiências.

É importante analisar estas dimensões de valor por parte do cliente porque costuma ser um erro comum a idéia de que existe uma maneira única de adicionar valor e diferenciação para uma dada oferta da empresa. É preciso compreender como cada uma dessas dimensões é afetada pela gestão da cadeia de suprimentos, e como esta última precisa levar em consideração estes distintos aspectos de valor ao cliente.

A dimensão conformidade com as exigências é traduzida pela capacidade que a empresa possui de oferecer exatamente aquilo que o cliente quer, e para a qual contribui a gestão da cadeia de suprimentos, ao criar seleção e disponibilidade. Marshall Fisher apud SimChi-Levi et Alii (2003, p. 215) designa esta característica como sendo a função de mediação de mercado da cadeia de suprimentos. Esta função de mediação é distinta da função física da cadeia de suprimentos, que consiste em converter as matérias primas em bens e despachá-los para os clientes.

Existem custos associados à mediação de mercado que se manifestam quando existem diferenças entre a oferta e a demanda. Quando a oferta supera a demanda, surgem custos de estocagem ao longo da cadeia de suprimentos. Analogamente, se a demanda supera a oferta, ocorrem perdas de vendas e provavelmente de participação no mercado.

As características das cadeias de suprimentos vão variar de acordo com o comportamento da demanda pelos produtos. Por exemplo, se a demanda por um tipo de produto for previsível, como ocorre com itens funcionais (fraldas; sopas prontas; caixas de leite longa vida), a mediação de mercado não é relevante. Para esses casos de itens funcionais, as cadeias de suprimentos são eficientes na medida em que reduzem os custos, focando na redução de estoques, na otimização dos transportes e outras ações correlatas.

Contudo, para itens da moda ou outros que evidenciem uma elevada variabilidade, a natureza errática da demanda pode gerar custos elevados devido à perda de vendas ou aos estoques excessivos. Nesses casos as cadeias de suprimentos devem ser responsivas, enfatizando lead times mais curtos, bem como uma maior flexibilidade, priorizando a rapidez ao invés dos custos.

Já a dimensão seleção de produtos envolve o fato de que existe uma ampla gama de produtos que se apresentam com uma enorme variedade de estilos, opções, cores e formas. Por 
exemplo, um automóvel pode estar disponível em três estilos distintos, 8 diferentes cores externas, quatro cores internas e ainda com transmissão automática ou manual, com um leque de diversas configurações possíveis. Tal circunstância provoca uma dificuldade para os varejistas, que é a necessidade de estocar muitas das diversas combinações e configurações dos produtos, pois é complicado prever a demanda dos clientes para um modelo específico.

Para enfrentar esta característica que certos produtos possuem existem três tendências de negócios bem-sucedidos: especialização na oferta de um tipo de produto; grandes lojas que permitem "comprar tudo em apenas um lugar" para uma enorme variedade de produtos; e grandes lojas que se especializam numa determinada área de produtos.

Existem algumas maneiras de contornar em parte o problema de ter que estocar uma grande variedade de configurações ou produtos. Algumas empresas, tais como a Dell Inc. que fabrica computadores montados sob encomenda, configuram o produto apenas quando chega um pedido, e com isso reduzem os estoques. Outras empresas, tais como os fabricantes de veículos, mantém grandes estoques em Centros de Distribuição, permitindo aos distribuidores enviarem pedidos de carros que não têm em estoque para os depósitos regionais, que podem expedi-lo quando necessário. Uma terceira alternativa consiste em oferecer um conjunto fixo de opções cobrindo algumas exigências dos clientes, como no caso da Honda, que oferece um número limitado de opções para os seus carros.

Vamos analisar agora a dimensão preço e marca. 0 preço dos produtos e o custo dos serviços associados constituem-se em aspectos fundamentais do valor ao cliente.

Ainda que eventualmente o preço não seja o único fator a ser considerado pelo cliente, existe uma pequena margem de variação de preços que costuma ser aceitável para determinados produtos. Contudo, se os produtos tiverem características de commodities, a flexibilidade com relação aos preços será reduzida. Nestes casos, as maiores possibilidades de obter vantagens em custos encontram-se nas inovações em suas cadeias de suprimentos.

Existe também um outro fator que influi no preço, que é a marca do produto. Em face da tendência atual observada, no sentido de que existem mais clientes dispostos a comprar em lojas que funcionam como supermercados, a importância das marcas aumenta, pois ela pode ser um indicativo de qualidade na mente do comprador. Por esta razão é que marcas como Mercedes e Rolex são associadas à qualidade e prestígio, e podem ser oferecidas por preços maiores do que os produtos similares que não possuem esta mística. Em casos assim, as cadeias de suprimentos precisam ser mais responsivas, ainda que isto implique em aumentos de custos, pois estes custos serão compensados por maiores margens decorrentes dos preços mais elevados.

Passemos a analisar a dimensão serviços com valor agregado. Observa-se que muitas empresas não são capazes de competir apenas com base no preço em uma economia com abundância de ofertas. Isto faz com que busquem novas fontes de receitas. Para obterem este resultado, as empresas desenvolveram ofertas com valor agregado que as diferencie das suas concorrentes, permitindo estruturas de preços mais lucrativas.

A oferta de serviços com valor agregado, tais como suporte e manutenção, podem ser elementos determinantes para a compra de alguns produtos, especialmente produtos técnicos. Há uma tendência observada no sentido de que as empresas estão acrescentando mais serviços aos seus produtos. As causas por trás desta tendência são: 
- O processo de "commoditização" dos produtos, que faz com que o preço seja um aspecto determinante para a compra, haja vista que as demais características são similares, fato que reduz a lucratividade e a vantagem competitiva.

- A necessidade de estreitar a proximidade com o cliente.

- O incremento da disponibilidade e da capacidade da tecnologia de informação e comunicação, aumentando a disponibilidade das ofertas.

Com relação ao último quesito, atualmente se constata que um importante serviço com valor agregado é o acesso à informação. Verifica-se um aumento do nível de relacionamento com as empresas que permitem o acesso dos clientes aos seus próprios dados, tais como pedidos pendentes, histórico de pagamentos ou pedidos recentes. Alguns clientes dão mais valor à possibilidade de conhecer o status de um pedido do que mesmo ao prazo de entrega, porque esta informação gera confiabilidade e possibilita um planejamento mais eficaz.

A capacidade dos clientes acessarem informações está se tornando um elemento fundamental na gestão da cadeia de suprimentos, haja vista que eles valorizam a transparência das informações. A Internet veio possibilitar isto e as empresas devem investir em sistemas de informação que suportem estas demandas. Por fim, passemos a analisar a dimensão relacionamentos e experiências. É possível afirmar que o nível final do valor ao cliente consiste numa conexão ampliada entre a empresa e os seus clientes, por intermédio do desenvolvimento de relacionamentos. Por exemplo, quando optamos por um determinado provedor de Internet, acabamos por criar vínculos que tornam difícil a mudança para outro provedor. Existe um tipo de relacionamento interessante, que conhecido como relacionamento de aprendizagem, com base no qual as empresas constroem perfis dos seus clientes e usam esta informação tanto para aumentar as vendas quanto para mantê-los.

Há o conceito de empreendimento um-a-um, no qual as empresas aprendem acerca de cada um de seus clientes por meio do gerenciamento de um banco de dados e comunicações interativas, de tal forma a vender para um dado cliente tantos produtos e serviços quanto forem possíveis, ao longo do período de relacionamento. 0 banco de dados é empregado para sugerir novas ofertas, a partir do rastreamento das necessidades e preferências dos clientes, e, num segundo momento, chegando até a adaptar as ofertas da empresa aos clientes.

Um processo de aprendizagem é algo que pode levar tempo, contudo torna-se difícil para os concorrentes repetirem a mesma estratégia. Sob a ótica do cliente, o processo de aprendizagem passa a oferecer para ele um maior leque de possibilidades, e isto acaba por fidelizá-lo.

\section{OS ELEMENTOS DO SERVIÇO AO CLIENTE:}

Verificamos em Ballou (2006, p.93) que a logística ao cliente é uma parte do conjunto de serviços oferecidos pela empresa. Ballou apresenta uma série de considerações importantes acerca do serviço ao cliente que julgamos merecer uma transcrição. Assim, Kyj e Kyj apud Ballou (2006, p.93) observaram:

... serviços ao cliente, quando utilizados de forma eficaz, constituem uma variável de capital importância que pode ter impacto significativo na criação de demanda e na manutenção da fidelidade do cliente.

Temos também a citação de Blanding apud Ballou (2006, p.93), para quem os serviços ao 
cliente:

... referem-se especificamente à cadeia de atividades de satisfação de vendas que começa normalmente com a formalização do pedido e culmina na entrega das mercadorias ao cliente, embora em uma variedade de situações possa ter continuidade na forma de serviço de apoio ou manutenção de equipamento ou qualquer outra modalidade de suporte técnico.

Mais recentemente, o serviço ao cliente passou a ser descrito em termos de um processo de preenchimento, que, conforme explica Doctker apud Ballou (2006, p.93), significa:

... o processo integral de atendimento do pedido do cliente. Isso inclui a recepção do pedido (por meio físico ou eletrônico), a determinação da forma de pagamento, seleção e embalagem das mercadorias, embarque, entrega, disponibilização dos serviços ao usuário final e acerto de eventuais devoluções de produtos.

Verificamos com fundamento nestas definições, que o conceito de serviço ao cliente é bastante elástico, e necessita estar em constante aperfeiçoamento, conforme se modificam os requerimentos de exigências dos clientes. Destaca-se que o serviço ao cliente é o elemento que associa de forma íntima a função logística com a função marketing nas organizações, em razão da estreita ligação que a praça ou ponto de venda possui com a distribuição física do produto.

Ballou (2006, p.94) assinala que muitas pesquisas têm sido realizadas para procurar compreender os elementos constitutivos do serviço ao cliente e como eles conduzem o comportamento dos compradores.

Em virtude de ser difícil para os clientes identificar o que os leva a agir de uma determinada maneira, definir exatamente o que constitui o serviço ao cliente é algo que está sujeito a múltiplas interpretações. Em Ballou também podemos encontrar o resultado de um dos trabalhos de pesquisa mais detalhados sobre este assunto, que procurou identificar os elementos que constituem o serviço ao cliente, a partir do momento em que se estabeleceu a transação fornecedor-cliente. Estes elementos são elencados nas seguintes categorias: prétransação; transação; e pós-transação.

Os elementos de pré-transação são aqueles que favorecem para que se instaure um ambiente para um bom serviço ao cliente. Compreendem desde um compromisso formal sobre as modalidades do serviço, tais como o tempo máximo de entrega de uma mercadoria após a formalização de um pedido, bem como os critérios de embarque ou ainda os procedimentos relativos à devolução da mercadoria.

Com relação aos elementos de pré-transação, Christopher registra que os mesmos estão relacionados com as políticas ou programas corporativos, tais como as declarações escritas sobre a política de serviços, a adequação da estrutura organizacional e a flexibilidade do sistema. Ou seja, são aspectos voltados tanto para a informação do cliente acerca do serviço que lhe será prestado, como também para a elaboração de planos de contingência que permitam a superação de eventuais imprevistos surgidos no decorrer do serviço, que impeçam ou retardem o cumprimento do pedido. 0 quadro a seguir apresenta alguns dos elementos pré-transação mais relevantes: 


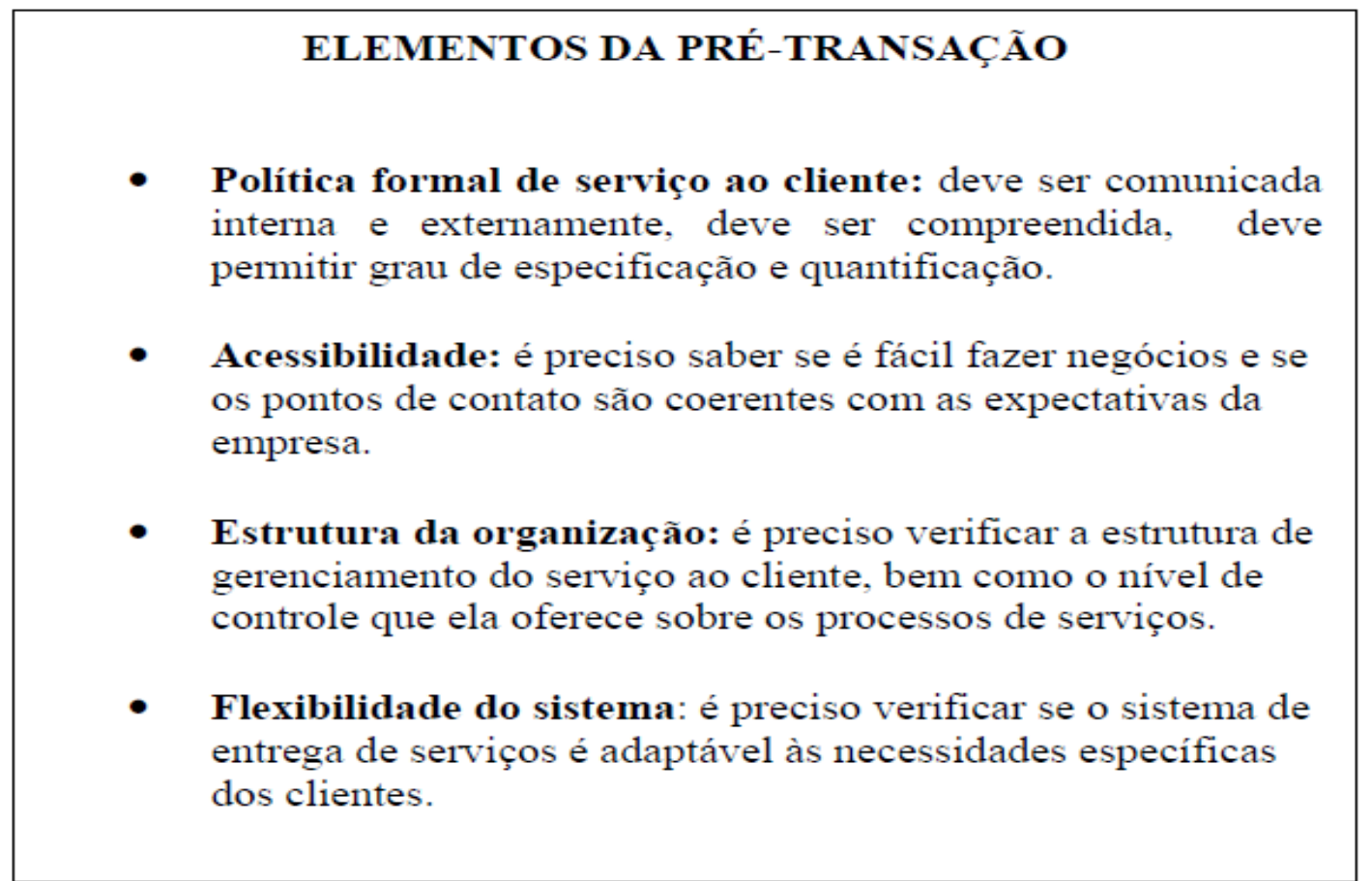

Os elementos de transação são aqueles que resultam diretamente na entrega do produto ou serviço ao cliente. Representam as variáveis que estão diretamente envolvidas no desempenho da função de distribuição física, tais como a confiabilidade do produto e da entrega. Por exemplo, a decisão quanto ao nível de estoques, a seleção da modalidade de transporte e a determinação do método de processamento dos pedidos são alguns exemplos desses elementos. 0 quadro a seguir apresenta alguns dos elementos de transação mais importantes:

\section{ELEMENTOS DA TRANSAÇÃO}

- Ciclo do pedido: deve ser verificado o tempo entre o pedido e a entrega, bem como a confiabilidade e variação da mesma.

- Disponibilidade de estoque: é preciso conhecer a proporção da demanda que é atendida por cada item presente no estoque.

- Taxa de atendimento do pedido: é preciso saber qual é a proporção dos pedidos completamente atendidos no tempo de espera declarado.

- Informações sobre a situação do pedido: é preciso verificar o tempo necessário para se responder uma pergunta do cliente sobre uma informação requerida ou mesmo se os clientes são informados sobre eventuais problemas ou se antes eles entram em contato. 
Por fim, os elementos de pós-transação representam o conjunto dos serviços necessários para dar suporte ao produto em campo, ou seja, estão relacionados ao suporte ao produto em uso. Por exemplo, assegurar aos clientes a possibilidade de repor mercadorias danificadas, bem como providenciar a devolução das embalagens usadas, tais como garrafas ou cilindros de gás, ou mesmo gerenciar reclamações, são espécies de elementos dessa categoria.

Normalmente, o elemento de pré-transação faz sentir seus efeitos depois da venda do produto, mas seu planejamento deve ser concebido nos estágios anteriores. 0 quadro a seguir apresenta alguns desses elementos:

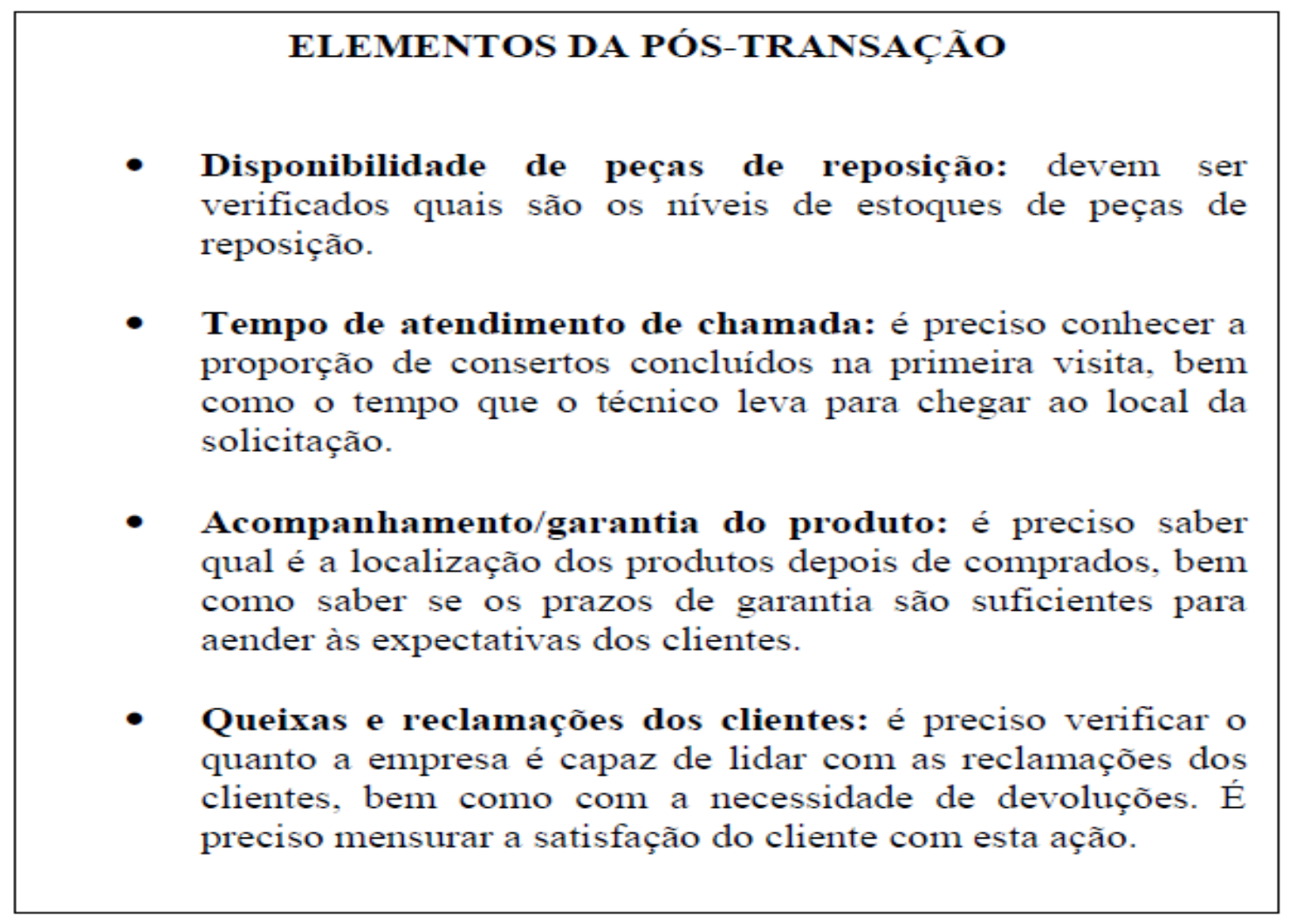

Com relação aos elementos que compõem o serviço ao cliente, é preciso destacar que, para uma dada situação particular de produto ou serviço, alguns desses elementos serão mais essenciais do que outros. Além disso, destacamos que os exemplos citados não perfazem uma lista fechada, ou seja, num determinado mercado podem existir outros fatores além daqueles citados, e é comum que, para um dado mercado específico, as empresas atribuam maior importância a diferentes elementos do serviço ao cliente.

Uma conclusão que devemos extrair do que foi visto é o fato de que, em razão da natureza múltipla do serviço ao cliente, e das diferentes exigências dos mercados específicos, é fundamental que todo negócio possua uma política claramente definida em relação ao serviço ao cliente.

\section{CONCLUSÕES:}

Neste artigo pretendemos demonstrar a íntima relação existente entre a manutenção da vantagem competitiva e a correta orientação da gestão logística orientada para o cliente. Nesse sentido, a função marketing passa a assumir o papel de orientadora da função logística.

A empresa que pretender se manter competitiva não poderá jamais descurar de manter 
ajustadas e alinhadas a estratégia da organização, com a estratégia do gerenciamento logístico, sob pena de vir a perder participação no mercado, em razão da perda de competitividade.

\section{REFERÊNCIAS:}

BALLOU, RONALD H. Gerenciamento da cadeia de Suprimentos / Logística Empresarial. 5a ed. - Porto Alegre: Bookman, 2006.

CHRISTOPHER, MARTIN. Logística e gerenciamento da cadeia de suprimentos: criando redes que agregam valor. - São Paulo: Thomson Learning, 2007.

SIMCHI-LEVI, DAVID ET ALII. Cadeia de Suprimentos, projeto e gestão. Trad. Marcelo Klippel. - Porto Alegre: Bookman, 2003. 